\title{
Códigos de la violencia en espacios económicos en Culiacán, Sinaloa, México
}

\author{
Iliana del Rocío Padilla Reyes \\ Universidad Autónoma de Sinaloa \\ ilianapadilla@uas.edu.mx
}

\author{
Nelson Arteaga Botello \\ Flacso. México \\ nelson.arteaga@flacso.edu.mx
}

Recepción: 20-07-2017

Aceptación: 05-02-2018

Publicación: 16-10-2018

\section{Resumen}

En este artículo, se examinan códigos de violencia detectados en espacios comerciales de la ciudad de Culiacán, estado de Sinaloa, México, como formas culturales de un orden social impuesto por grupos del crimen organizado. La investigación muestra que, en este tipo de ciudades, tanto criminales como ciudadanos y autoridades construyen mecanismos para contener y mediar la violencia en el territorio. Esto se logra a través de acuerdos informales que se desarrollan en diferentes sectores de la sociedad y que se caracterizan por relaciones asimétricas de poder entre empresarios, autoridades gubernamentales y organizaciones criminales. Se trata de códigos que se presentan además de manera diferencial, según los órdenes de gestión territorial que establecen grupos del crimen organizado para diferentes áreas de la ciudad. La información que se analiza es el resultado de un trabajo de observación participante y entrevistas formales, desarrollado entre 2012 y 2014, en dos sectores con diferentes estratos socioeconómicos e indicadores delictivos.

Palabras clave: códigos de la violencia; inseguridad; seguridad; narcotráfico

Abstract. Codes of violence in economic spaces of Culiacán, Sinaloa, Mexico

In this article, we examine codes of violence detected in commercial spaces in the city of Culiacán, Sinaloa, Mexico, as cultural forms of a social order imposed by organized crime groups. The investigation shows that criminals, citizens and authorities build mechanisms to contain and mediate violence in the territory in these types of cities. This is achieved through informal agreements that are reached in different sectors of society and characterized by asymmetric power relations between business owners, government authorities and criminal organizations. The codes are set in a differential manner according to the territorial management orders established by organized crime groups for different areas of the city. The information analyzed in this study is the result of fieldwork conducted in the period 2012-2014 in two sectors of the city with different socioeconomic strata and crime rates.

Keywords: violence codes; insecurity; security; drug trafficking 


\author{
Sumario \\ 1. Introducción 5. Resultados de la investigación \\ 2. Seguridad y códigos de la calle 6. Conclusiones \\ 3. Metodología Referencias bibliográficas \\ 4. Los sectores estudiados Anexo metodológico
}

\title{
1. Introducción
}

El conjunto de narraciones que se presenta en este artículo muestra, de manera repetida, que en Culiacán, Sinaloa, se ha constituido un cierto orden social, en el contexto de la inseguridad que vive la ciudad. Culiacán es una urbe de tamaño medio, con 858.000 habitantes, ubicada en el noroeste de México, la cual se ha distinguido por mantener durante décadas los más altos indicadores de homicidio y por ser uno de los centros de operaciones del Cártel de Sinaloa ${ }^{1}$. El orden social que se ha constituido en la ciudad se caracteriza por la institución de códigos de la calle o del barrio, que permiten a los actores desarrollar sus actividades rutinarias con cierta confianza y tranquilidad, a pesar del constante riesgo que les genera la violencia (Anderson, 1999; Matsueda et al., 2006. Como sugieren los resultados de las entrevistas realizadas en esta investigación, empresarios, policías y criminales organizados comparten estos códigos, los cuales se construyen a partir de claras asimetrías de poder y estatus, en las que participan tanto quienes tratan de imponer un orden por medio de la fuerza - legítima o ilegítima- como aquellos que tratan de mantenerse alejados de la violencia. Estos últimos, incluso, se adaptan a ese orden para garantizar su seguridad.

En este sentido, ¿`cómo es posible que actores tan distintos en un espacio urbano marcado por la violencia logren establecer un cierto orden social? La presente hipótesis apunta a que en la ciudad de Culiacán — como seguramente está sucediendo en otras ciudades mexicanas - la inseguridad no puede entenderse como un escenario divido entre criminales, empresarios y autoridades, sino que existen mecanismos y vasos comunicantes, a través de los cuales estos actores negocian y establecen acuerdos que funcionan a partir de relaciones asimétricas de poder. Desde esta perspectiva, el crimen organizado ha creado un orden social en la ciudad, en el cual cada uno de los actores instituye o asume una serie de códigos de comportamiento respecto a la violencia, a través de los cuales construye las rutinas de su vida cotidiana. Se trata de códigos que además se configuran de manera específica en cada espacio, según las negociaciones, los acuerdos y las relaciones de poder entre los actores involucrados: mientras que en las zonas empobrecidas y marginadas el narcotráfico establece una gestión territorial de la violencia con un margen de negociación

1. De acuerdo con datos del Semáforo Delictivo, la tasa de homicidios en Culiacán es de 51,4, mientras que la media nacional es de 14,2. 
menor entre los actores, en las zonas acomodadas económicamente y de altos ingresos, es posible encontrar mayores mecanismos de negociación entre los participantes.

En este artículo, se presentan algunos de estos códigos que rigen el comportamiento de empresarios, empleados y otros agentes económicos, en escenarios conflictivos de la ciudad de Culiacán. Específicamente, se examina cómo se desarrollan de manera diferencial los códigos de violencia en dos sectores que se encuentran en distintos espacios de la ciudad. ${ }^{2}$ El primero, denominado en este estudio Sector Central, abarca una avenida en la que se aglomera la actividad empresarial de una de las colonias de mayores ingresos, céntrica y sujeta a un proceso de tercerización. En apariencia, se trata de un lugar seguro, a pesar de que, según datos de la Secretaría de Seguridad Pública Municipal, es uno de los espacios con la más alta incidencia de delitos en la ciudad. ${ }^{3}$ El segundo, denominado Sector Sur, está conformado por dos avenidas ubicadas en el sur de la ciudad, donde se encuentran colonias populares que concentran la actividad comercial y presentan las más altas tasas de residentes detenidos por la policía. Aparentemente, se trata de un lugar inseguro, con infraestructura urbana descuidada, pero donde, según los entrevistados, los grupos criminales han establecido un control de la violencia que permite a los empresarios trabajar con cierta tranquilidad.

Pese a que estos espacios se encuentran geográficamente distantes y son socialmente diferentes, comparten el hecho de que en ellos se han configurado arreglos específicos que imponen regulaciones sobre el tipo de comportamiento que se debe tener en la calle. Quienes viven, trabajan, visitan o transitan regularmente por estos espacios han aprendido estas reglas. Con quién hablar, por dónde no caminar, en quién confiar y qué hacer en el barrio son conocimientos valiosos para la supervivencia de los negocios de los empresarios de ambos espacios, y se obtienen mediante la práctica, en la experiencia y en la convivencia con otros actores.

El objetivo de este análisis es mostrar que los códigos de violencia no se establecen de la misma forma en los diferentes escenarios, en lo referente al papel de los participantes y los arreglos que instituyen. Mientras que en el Sector Central se desarrollan códigos diferenciales, que varían según las constantes negociaciones de los actores, en el sur popular, los grupos criminales imponen códigos a los que se tiene que adaptar el resto de los participantes. En el primer espacio, los grupos criminales generan dinámicas de "protección", centradas en ciertos comercios en particular, y se despreocupan aparentemente por cubrir territorios completos. Por tanto, aquellos negocios que no tienen este tipo de «protección» se ven obligados a establecer estrategias de autoprotección más estrictas, así como a reconocer y obedecer reglas de conducta específicas, para

2. Se cambiaron los nombres para proteger la identidad de los entrevistados. No obstante, se respetan las descripciones.

3. Según los datos que proporcionó la Secretaría de Seguridad Pública y Tránsito Municipal de Culiacán en el año 2011. 
garantizar la seguridad de sus espacios de trabajo. En cambio, en el segundo sector, los grupos delictivos generan dinámicas de control territorial, sobre todo contra asaltos o robos a comercios. Es esta diferencia - la forma como el crimen despliega su presencia- la que se considera central para entender la construcción de los códigos de violencia.

Para mostrar este proceso de construcción de órdenes sociales diferenciales, el artículo abre con un apartado en el que se desarrollan algunos conceptos básicos para el análisis. En esta primera parte, se examinan conceptos que permiten entender cómo en ciertos escenarios de inseguridad y violencia los actores tienden a generar una conciencia práctica y ciertos códigos de la calle (Anderson, 1999): sistemas de reglas informales que permiten el gobierno de un territorio en contextos de violencia. En la segunda parte, se expone la metodología utilizada en el trabajo de campo. En el tercer apartado, se describen dónde se ubican los espacios de estudio en Culiacán. En la cuarta parte, se identifican y estudian los códigos de violencia en estos lugares. Se trata de caracterizar a los actores que participan, así como las normas y sanciones que se establecen en ambos espacios, para buscar las diferencias y coincidencias en los acuerdos informales y en la actuación de empresarios, policías y supuestos criminales. En la cuarta parte del artículo, se abordan las conclusiones derivadas del estudio.

\section{Seguridad y códigos de la calle}

Como sugiere Giddens (1997), las personas tienden a desarrollar un marco de seguridad, a través del despliegue de un número determinado de rutinas, aun en los contextos marcados por la violencia y la inseguridad. La gente hace frente a los peligros a partir de fórmulas emocionales y de comportamientos que se convierten en parte de su vida cotidiana (Cohen y Felson, 1979). Dichas fórmulas resultan medios de protección frente al peligro que los otros pudieran representar y son la sustancia básica de las interacciones cotidianas (Bruce y Wright, 2010). Cuando se logra construir un sentimiento de seguridad, aun a pesar de los constantes riesgos que se enfrentan en una sociedad, es porque, según Giddens (1997), los sujetos han logrado construir una seguridad ontológica; es decir, han logrado tener una conciencia práctica de lo que sucede a su alrededor.

Esta seguridad permite a los sujetos realizar actividades habituales con cierta confianza, y dejar en un segundo plano las preocupaciones que pudieran generarles angustia y ansiedad - tales como la vulnerabilidad ante el peligro y la probabilidad de sufrir una agresión a su persona o sus posesiones (Giddens, 1997; Coaffe et al., 2009)—. A través de esta conciencia práctica, los actores saben tácitamente el modo de «ser con» los «otros» en los distintos contextos de vida social, sin «ser capaces de darle una expresión discursiva directa» a dicha conciencia (Giddens, 2003: 24). Esta última es, en definitiva, «el ancla cognitiva y emotiva de los sentimientos de seguridad ontológica, y está vinculada a la rutinización de la actividad humana» (Giddens, 1997: 52). Las 
rutinas diarias de interacción social, la manera como los actores se conducen con los otros en su entorno y como se identifican entre ellos, están relacionadas claramente con las formas de control social de la angustia, según Threadgold y Nilan (2009).

Estas rutinas permiten a los individuos desarrollar una especie de "coraza protectora» que les genera un marco de confianza para actuar en la vida diaria, sin tomar demasiada conciencia de los constantes riesgos que afrontan (Jacobs y Wright, 2010). Dicha coraza es más bien un sentimiento de irrealidad, pero permite desplazar a un segundo plano los posibles acontecimientos que amenazan la integridad corporal de las personas (Giddens, 1997: 57). Sin embargo, Giddens (2003) establece una diferencia entre los comportamientos rutinarios prácticos y los estratégicos: mientras que los primeros se realizan más por inercia que de manera planificada, los estratégicos conllevan la conciencia discursiva (aquello que los actores expresan verbalmente) y los recursos de poder (estrategias de control). Así, un ambiente inseguro en el que impera el crimen y la violencia no es necesariamente un ambiente caótico y desordenado, pues, si se explora con cuidado, posiblemente aparezca un orden social inteligible para quienes viven en él (Tseloni y Farrell, 2002). Para una importante parte de la literatura sociológica (Lupton, 1999; Walklate, 1998, 2001), la capacidad de leer este orden se aprende y permite a las personas continuar con sus vidas, pese a la presencia de escenarios de alto riesgo.

Al respecto, Anderson (1999) ha señalado que, en contextos de alta criminalidad y violencia delictiva, las personas aprenden a negociar las condiciones de peligro, ya que reconocen lo que el autor llama el código de la calle: un conjunto de prescripciones y proscripciones - o reglas informales de comportamiento organizado- que permite reconocer las situaciones que pueden transformar a una persona en el objetivo de un acto criminal. Para este autor, el código de la calle emerge de forma más clara cuando no hay presencia de la policía —o ésta es prácticamente inexistente-, lo que obliga a las personas a desplegar comportamientos rutinarios prácticos y estratégicos, para lograr garantías de seguridad y protección.

Esta capacidad de comprender el código de la calle es una habilidad que se aprende en el día a día de la vida cotidiana (Walklate, 2011; Wilcox et al., 2003). Como toda habilidad social, no solo es una experiencia individual, sino colectiva (Heitgerd y Bursik, 1987), que permite la construcción de relaciones sociales estables y de confianza, aun pese a la presencia de un claro contexto de incertidumbre (Sennett, 2012). Las habilidades para decodificar el entorno implican la puesta en marcha de una serie de estrategias de convivencia, que se cristalizan a través de mecanismos de comunicación y que transmiten códigos y símbolos específicos sobre cómo comportarse en una situación particular (Arteaga et al., 2016; Green y Singleton, 2006; Hindelang et al., 1978).

El sentimiento de inseguridad en un vecindario, calle o zona comercial depende, por tanto, de la comprensión y aceptación del código de la calle. Estos códigos regulan las pautas de conducta en los espacios urbanos y proporcionan, al mismo tiempo, mecanismos para que aquellos que tienen inclinación 
hacia la agresión tengan comportamientos racionales (Anderson, 1999). En un escenario en el que la policía ha perdido el control de la seguridad pública —o incluso donde la misma policía genera inseguridad-, las personas y grupos desarrollan sistemas de acuerdos informales con quienes pueden ser una amenaza a sus intereses, para garantizar la protección y la armonía. Así, respetando los códigos, las personas pueden identificar los comportamientos de los otros, prever y evitar los conflictos, al tiempo que realizan sus actividades con cierta confianza.

Como se verá a continuación, en espacios conflictivos con alta incidencia criminal, como los casos que aquí se analizan ${ }^{4}$, se crean acuerdos informales — códigos de la calle- derivados de la necesidad que tienen los actores de mediar y contener la violencia. Esto ha permitido la construcción de una seguridad que define comportamientos rutinarios prácticos y estratégicos: tanto en las actividades que ya realizan por inercia, porque «así se hacen las cosas allí», como en aquellas que siguen bajo un esquema de planeación para protegerse como realizar negociaciones informales con el crimen, entre otras medidas-. Los acuerdos y las rutinas que se generan permiten conformar un marco de actuación y de convivencia, donde los actores realizan sus actividades cotidianas con cierta seguridad, afrontando así escenarios de posible riesgo.

Sin embargo, es necesario mencionar que estos códigos, así como el orden social que generan, están marcados por el control social armado y violento de ciertos grupos. De esta manera, como sugiere Maldonado (2014a), es posible observar un orden informal que establece una solidaridad forzada - la cual regula la vida cotidiana de los espacios estudiados a través de infligir dolor y muerte a sus pobladores—, así como procesos de violencias silenciosas mecanismos a través de los cuales las personas juzgan e internalizan los actos de violencia cotidiana-. Ambos conceptos, como bien sugiere Maldonado (2014a), permiten entender los efectos de alianza y ruptura de los grupos sociales que se encuentran ligados, directa o indirectamente, a las actividades que realizan ciertos grupos criminales vinculados al tráfico de drogas.

Para analizar estas dinámicas que se instituyen entre los actores, en espacios de la actividad empresarial en la ciudad de Culiacán, se analizan a continuación dos sectores de actividad económica que, a pesar de que cuentan con características sociales muy diferentes, han instituido marcos de solidaridad forzada, a través de ciertos códigos que permiten que delincuentes, empresarios y autoridades moderen las relaciones de conflicto en el espacio, creando así un cierto orden social.

\section{Metodología}

La muestra. La selección de los espacios de estudio se determinó a través de dos criterios: se identificaron lugares donde se cometen los delitos en la ciudad y lugares donde residen los ejecutores de estos delitos. En el primero, se

4. Según datos de la Secretaría de Seguridad Pública y Tránsito Municipal de Culiacán. 
identificaron los barrios que presentaron el mayor número de reportes ante la policía por robos a comercios, asaltos a transeúntes, robos a casa habitación, homicidios, lesiones, portación de armas, extorsiones y otras agresiones, entre los años 2010 y 2014. Para el segundo criterio, se consideraron los barrios que tuvieron la mayor tasa de residentes que fueron detenidos por la policía durante esos mismos años (SSPyTM, 2011).

Método. A partir de estos criterios, se identificaron en esos barrios tres bulevares donde se concentra la actividad empresarial. Se estudió un sector de estrato bajo, con los indicadores más altos de «residencia de detenidos» — donde viven los delincuentes—, según los datos de la policía, y de imagen urbana deteriorada. De igual forma, se seleccionó un sector de estrato alto, el cual presenta los indicadores más altos de incidencia delictiva — donde se cometen los delitos-y que es un espacio donde la autoridad local ha cuidado la imagen urbana. El primero se denomina aquí Sector Sur y el segundo Sector Central.

Análisis. Se partió del supuesto de que en estos sectores o espacios económicos no solo existe el intercambio de bienes y servicios mediados por la violencia, sino que en ellos se generan lazos de comunidad y sociabilidad, en los cuales confluyen empresarios, empleados, clientes, proveedores, habitantes, criminales y policías. En este sentido, el sector se constituye en una unidad de estudio en el que esos distintos actores trabajan, viven e interactúan en el mismo espacio físico y social, llegando a establecer patrones de comportamiento, significados e historias, con base en las vivencias que comparten. Aquí cabe subrayar que cada uno de estos actores da cuerpo a un entramado social en el que, pese a sus diferencias y heterogeneidad, comparten una estructura cultural particular que codifica y significa las lógicas de inseguridad y violencia que ahí se viven.

Entender las formas culturales que se expresan en acuerdos y negociaciones sobre la violencia a través del habla sobre el crimen que despliegan sus actores implicó llevar a cabo un trabajo de observación participante de 2012 a 2014, en el que además se realizaron 64 entrevistas formales —a través de un cuestionario de preguntas semiestructuradas-e informales. ${ }^{5}$ El objetivo

5. Uno de los investigadores se internó en las comunidades de estudio como cliente y estableciendo acuerdos con algunos empresarios para pasar como empleado, buscando crear rapport con los actores en sus dinámicas cotidianas - del total de las entrevistas, solo se logró rapport en 38 casos- - . Se documentó la actividad cotidiana de los actores de la comunidad y sus estrategias frente a posibles escenarios de inseguridad. La información que se recabó fue capturada en diarios de campo, en grabaciones de voz y en fotografías. Por su parte, en las entrevistas semiestructuradas se buscó documentar la visión de la comunidad sobre sí misma, sobre los otros, el espacio y los códigos ante la violencia: cómo perciben el corredor, sus negocios, los delincuentes, la violencia y las reacciones ante esta, los acuerdos y las normas informales. Los formatos se elaboraron de manera diferenciada para cada tipo actor, de acuerdo con sus características -empleados, empresarios, microempresarios, clientes, etcétera- y el corredor donde se ubicaban, con preguntas flexibles y dando lugar al diálogo. Finalmente, al término del trabajo, se llevó a cabo un ejercicio de «devolución de la información» con algunos de los actores que previamente se entrevistaron, con el fin de cerrar vacíos de información o sobre interpretaciones. 
fue obtener información que permita reconstruir e interpretar los significados de las acciones y expresiones de los participantes, y revelar los códigos a través de los cuales es posible dar cuenta de las condensaciones de sentido en que se observan las tensiones, los conflictos y los acuerdos que se generan frente a las lógicas de la inseguridad y violencia en que viven colectivos e individuos.

\section{Los sectores estudiados}

El Sector Central se encuentra en una zona contigua al casco histórico (ver ilustración 1), junto a los márgenes del río Tamazula. Esta área, con 8.715 habitantes (INEGI, 2010), se ha caracterizado por ser una zona residencial de estratos altos y es el sector de la ciudad con mayor actividad comercial, después del centro (INEGI, 2010a). La colonia fue creada en 1960, sobre terrenos contiguos a los márgenes del río y al centro de la ciudad y se planteó como un desarrollo habitacional para familias de altos ingresos. No obstante, desde la década de los noventa, la colonia fue tomando fama de ser el lugar de convivencia de hijos de narcotraficantes: durante los fines de semana las calles de este sector se caracterizaban por ser en punto de reunión de adolescentes que acudían a escuchar música que hace alusión al narcotráfico (narcocorridos), dar vueltas en los coches e ingerir bebidas alcohólicas en la vía pública ${ }^{6}$. Hasta hace una década, era una zona habitacional con escasa actividad empresarial, pero en los últimos años se han conformado corredores urbanos que tienen cada vez mayor demanda, sobre todo en giros comerciales dirigidos a los jóvenes.

La actividad comercial está orientada a un público con alto poder de consumo - por lo que es posible encontrar tiendas de ropa de moda, restaurantes y cafés-. Esto ha generado, entre otras cosas, que haya reuniones festivas cada fin de semana en las principales avenidas de este sector. Los adolescentes de la zona juegan carreras de coches, ingieren bebidas alcohólicas en la vía pública, escuchan música a todo volumen en sus automóviles e incluso detonan armas de fuego. Sin embargo, vecinos y comerciantes consideran que «si uno no se mete con ellos, no pasa nada", por lo que a pesar de que intentan evitarlos en la calle, los tratan bien como clientes de sus comercios.

Estadísticas de la Secretaría de Seguridad Pública indican que, entre los años 2000 y 2010, en estos lugares - después del centro de la ciudad - se presentó el mayor número de delitos, como asaltos, robos de coches, robo a negocio comercial, entre otros. En ese período, se reportaron 1 mil 511 delitos, pero solo se detuvo a 47 personas. En 2011, se reportaron 167 robos de coches y 117 robos a comercios y a viviendas (SSPyTM, 2011).

Por el contrario, las avenidas en el Sector Sur se ubican en una zona popular conformada por cinco colonias, donde habitan 26.465 personas (ver ilustración 1). Estas colonias se fundaron como asentamientos irregulares - entre 1970 y 1980 - , debido a la migración que se generó, por un lado, por el

6. El Universal (2014), «Narcojuniors y pandillas prenden focos rojos en norte». Periódico El Universal, jueves 6 de noviembre de 2014. 
éxodo del campo a la ciudad que vivió en su conjunto el país en esos años y, por otro, por la Operación Cóndor — destinada a combatir el narcotráfico-, que se estableció en particular en Sinaloa, lo que obligó a muchos campesinos a abandonar sus tierras para encontrar seguridad en las ciudades. Los espacios de acogida solían ser lugares densos y de alta marginación, ocupados por una primera generación de migrantes provenientes del valle agrícola o de la sierra. Hoy en día, estos asentamientos se encuentran consolidados como colonias de estratos mayormente bajos y medio bajos, con viviendas sencillas de autoconstrucción, con todos los servicios básicos (Sedesol, PMDUC, 2012).

Ilustración 1. Mapa de ubicación de los sectores estudiados respecto a la geografía de la ciudad, y ubicación de la ciudad respecto a la geografía del país

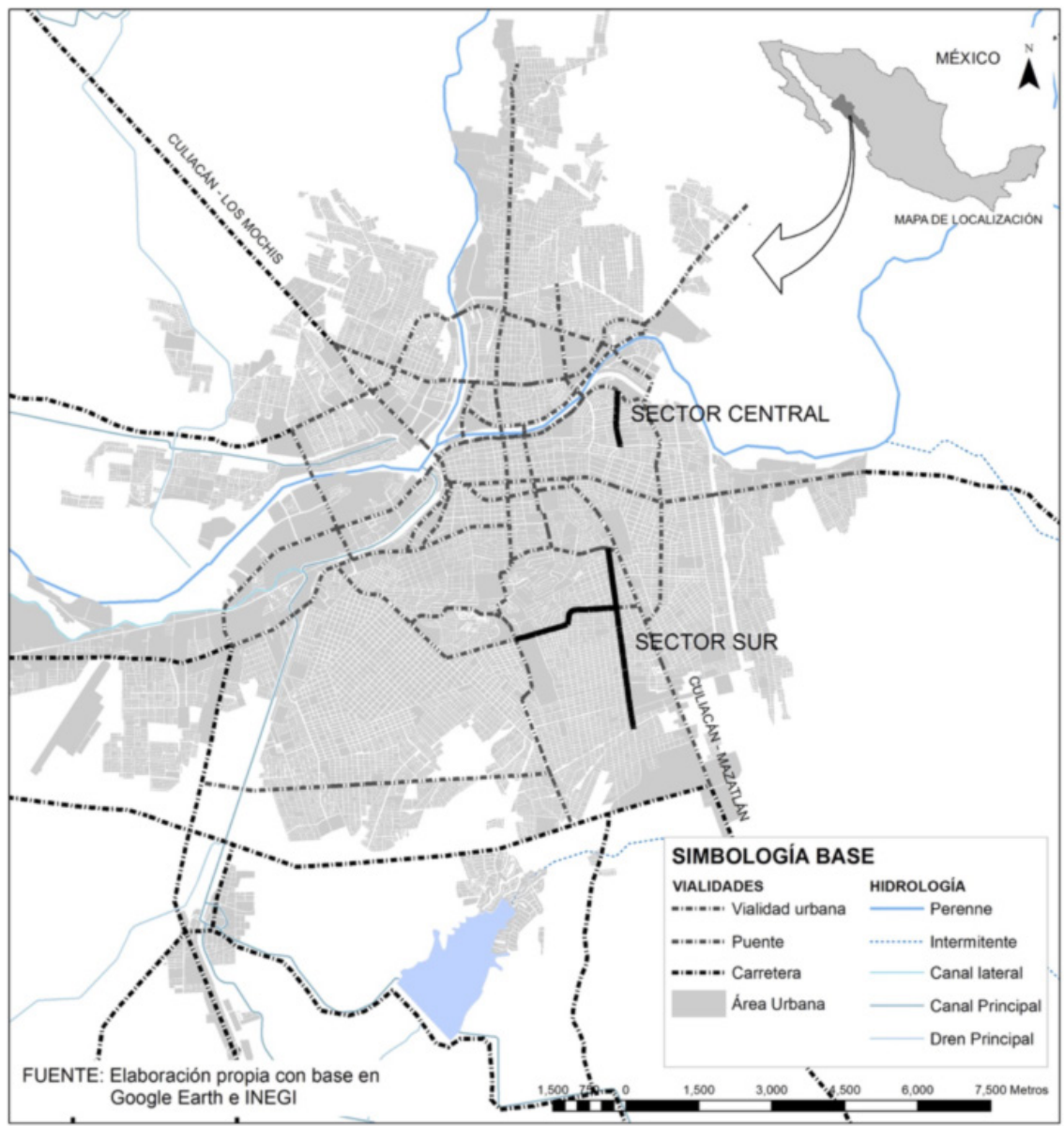

Fuente: elaboración propia con base en Google Earth e INEGI. 
En la última década, en la zona se han creado un par de corredores comerciales. La actividad comercial es definida por los empresarios como «buena», porque hay mucha afluencia de personas y vehículos, ya que esas calles son las principales arterias de circulación del sector y allí se concentran las paradas de los autobuses. La oferta se dirige a un público de poder adquisitivo bajo a medio, y la mayoría de los negocios son familiares, con no más de dos empleados - aunque también se encuentran algunas sucursales pequeñas de cadenas comerciales, como farmacias y supermercados- Los locales comerciales son modestos y la imagen urbana está descuidada: las calles están llenas de hoyos o baches, en muchos de los tramos carecen de banquetas y la iluminación por las noches es deficiente.

Este sector presenta las más altas tasas de residentes detenidos, entre 2000 y 2010, con un alto porcentaje de jóvenes menores de 20 años (SSPyTM, 2011). Los empresarios manifiestan sentirse seguros y tranquilos al desarrollar sus actividades, a pesar de que con frecuencia se llevan a cabo homicidios en las calles — como producto de «ajustes de cuentas» ${ }^{7}$ - y de que las deficiencias en la infraestructura incrementan la sensación de inseguridad, en particular durante las horas de la noche.

Tanto en el Sector Central como el Sector Sur se ha establecido un orden social específico, que es determinado a partir del acoplamiento de la acción de tres actores en particular: empresarios, criminales y policía (estatal y municipal). Estos actores instituyen códigos de violencia, solidaridades forzadas y violencias silenciosas. Aunque los actores sociales participan en cierta medida en la institución de los códigos de la violencia en los espacios urbanos económicos aquí analizados, algunos ejercen mayor poder sobre otros, al propiciar y vigilar que dichas regulaciones se cumplan.

\section{Resultados de la investigación}

En este apartado se desarrollan los resultados de las entrevistas con empresarios y sus empleados en los dos sectores analizados en la ciudad de Culiacán, Sinaloa. Primero, se presentan los actores que intervienen en las negociaciones de los códigos de la violencia; en segundo lugar, se identifican las normas y sanciones que se establecen con estos códigos; y por último, se narran las experiencias de los entrevistados en los espacios comerciales en ambos sectores.

\subsection{Los actores: "los que andan bien" $y$ "los que andan mal»}

Los empresarios entrevistados en los espacios analizados se refieren con frecuencia a los sujetos que originan y controlan la violencia como «los que andan

7. Para referirse a los asesinatos que son cometidos por los grupos criminales contra sus propios miembros, los entrevistados utilizaron la frase «ajustes de cuentas», quizás como una forma de diferenciar este tipo de asesinatos y, de alguna manera, clasificarlos como «justos», debido a que son prácticas propias de esas organizaciones para sancionar los actos que desafían sus normas. 
mal». En el Sector Sur, donde el control se ejerce de manera territorial, los empresarios identifican dos tipos de actores como «los que andan mal»: los narcotraficantes o los sicarios de los narcotraficantes, así como los asaltantes o ladrones. Estos últimos se dividen en los «tarántulas», que son adictos a las drogas y roban por oportunidad, y los asaltantes o ladrones, quienes comenten estos delitos de forma recurrente y sistemática. En cambio, «los que andan mal» en el Sector Central, donde el control de la violencia se establece a través de negociaciones directas entre empresarios y grupos criminales, son los narcotraficantes o sus sicarios, los asaltantes y ladrones, al igual que los llamados narcojuniors, es decir, los hijos de los narcotraficantes.

Los empresarios y clientes entrevistados en los negocios del Sector Central se consideran del lado de «los que andan bien», porque afirman no estar involucrados en el narcotráfico. Experimentan, sin embargo, una serie de sentimientos encontrados, de rechazo y admiración, hacia aquellos que «andan mal». Por un lado, por la forma en que ostentan su poder, a través de coches de lujo, ropa de marca y capacidad por evadir la ley, y, por el otro, por la autoridad que representan, así como por la protección que generan frente a las dinámicas criminales que afectan a comercios y viviendas.

Para los comerciantes del Sector Central, reconocer las diferentes categorías de «los que andan mal» y detectarlos en sus negocios significa diferenciar entre el posible beneficio y el riesgo. Personas que trabajan o viven del dinero del narcotráfico son acogidas como buenos clientes o protectores, mientras que los asaltantes y ladrones son considerados indeseables. Decodificando la portación de cierta ropa, evidencias de cirugía estética, gestos y actitudes, se puede distinguir entre el «hijo del narco», "el narco», "el sicario», «el ayudante del narco», «la amante del narco», «la hija del narco», «el imitador del narco» y «el asaltante». Según los empresarios, decodificar o interpretar los signos que portan aquellos que «andan mal» es importante para garantizar la supervivencia del negocio.

Algunos de los empresarios del Sector Central, que se consideran que «andan bien», reconocieron tener cierto tipo de protección, arreglos, parentesco e incluso padrinazgo de alguna persona involucrada en el narcotráfico ${ }^{8}$. Otros no tienen una relación directa, pero de cierta manera toleran sus prácticas. Aunque algunos reconocieron que reciben recursos de procedencia ilícita, a manera de inversión para sus negocios, consideran que ellos son personas trabajadoras que no cometen delitos. Sus vínculos con el narco son vistos por ellos mismos como «indirectos»; «todos en Culiacán conocemos a algún narco», argumentan. En la búsqueda de certidumbre en el lugar en el que desarrollan sus actividades, los empresarios reconocen las prácticas de los otros como propias del entorno y se relacionan y establecen negociaciones con los diversos actores que participan en el espacio, en diferentes grados, desde tolerar

8. Nos referimos a las diversas actividades que se realizan en el narcotráfico: transporte de drogas al por mayor o al por menor, distribución, manejos financieros de los recursos del narcotráfico y grupos de protección, entre otros. 
o permitir sus prácticas, por los lazos de solidaridad forzada, hasta involucrarse en la reproducción de estas últimas.

Antonio, por ejemplo, dice que gracias a que tienen un "padrino» - refiriéndose a algún narcotraficante- sus restaurantes están protegidos. Él es el gerente general de una empresa que tiene sucursales en el Sector Central y en otras zonas de estratos altos: «En esta avenida, de aquí para allá, a todos han asaltado, y de aquí hacia allá también — apunta con su dedo de un lado al otro de la calle, desde los límites del establecimiento hacia la derecha y hacia la izquierda-. A todos, menos a nosotros». ${ }^{9}$

Su empresa, según el entrevistado, es respetada por los asaltantes y ladrones, e incluso por los sicarios, porque sus exteriores son lugares "protegidos contra asesinatos".

Entre los que «andan bien» y los distintos empresarios que "andan mal» hay un tercer actor: los policías. Los empresarios entrevistados en el Sector Central dijeron desconfiar de la actuación de la policía. Gustavo, por ejemplo, que tiene un negocio de comida ubicado en ese lugar, comentó, durante una entrevista, que no confía en los cuerpos de seguridad pública desde la última vez que lo asaltaron afuera de su empresa y le quitaron su camioneta nueva, el teléfono y su billetera. Ante estos hechos, la actuación de los oficiales le pareció, según dijo, «sospechosa». La policía llegó unos minutos después de que hiciera la llamada de reporte, y cinco minutos más tarde, allí mismo, le informaron que había «aparecido" su camioneta a unas cuadras del lugar — aunque fue informado que no habían detenido a nadie ni habían recuperado sus pertenencias-. Según el parte de la policía, los ladrones abandonaron la camioneta en el sitio, momentos después de haberla robado al empresario. «(...) (Los policías) me dijeron que no denunciara, que no tenía caso. También me dijeron que darían rondines y vendrían a que les firmara, y me pidieron propina... les piden a todos propina. Yo no les daba, pero a partir de ese momento comencé a darles, quizás por miedo». ${ }^{10}$

Daniel, el propietario de un comercio de helados en el Sector Central, fue asaltado en su negocio por un sujeto que apuntó a los presentes con una pistola. El asaltante robó la caja con el dinero del día y despojó a los clientes de sus objetos personales, incluso al propio Daniel, quien tuvo que entregar su cartera y su tableta electrónica. Después de que Daniel presionara el botón de pánico, la policía acudió al lugar y el empresario interpuso la denuncia y proporcionó las grabaciones de las cámaras instaladas, aunque, según cuenta, las autoridades no dieron seguimiento al caso.

Los empresarios del Sector Central intuyen que los agentes de la policía son parte del problema de inseguridad que enfrentan en la zona. Estos podrían jugar un papel de autoridad en un doble sentido. Por un lado, en el desempeño

9. Entrevista con Antonio, empresario en el Sector Central en Culiacán, Sinaloa, México. Se llevó a cabo el 26 de abril de 2014.

10. Entrevista con Gustavo, empresario en el Sector Central en Culiacán, Sinaloa, México. Realizada el 9 de abril de 2014. 
formal que tienen como autoridad, velando por el orden social; por el otro, de manera informal, instituyendo códigos de actuación respecto a la violencia, a través de los cuales establecen cuotas de protección - bajo el nombre de «donativos voluntarios»-, las cuales se interpretan como impuestos ilegales.

A diferencia del Sector Central, los empresarios en el Sector Sur no tienen que establecer mecanismos de negociación individual con los grupos criminales de la zona, ya que estos últimos establecen una estrategia de control y protección de carácter más territorial. Esto implica que no necesitan, aparentemente, tener un "padrino", o conocer a un narcotraficante, para garantizar la seguridad y prosperidad de su negocio - aunque la mayor parte de los entrevistados refirió que sí conocen a alguno-. Pero también eso implica que la policía presenta otros patrones de comportamiento en la construcción del código de violencia: al parecer, están sujetos en mayor medida al control y los códigos del narcotráfico, lo que implica que están sujetos a las lógicas de la solidaridad forzada que ellos establecen.

De la participación de la policía en los códigos, por ejemplo, se puede mencionar el testimonio de Antonia, médica jubilada del Instituto Mexicano del Seguro Social y empresaria. Recuerda que la violencia que enfrentaban los negocios en su barrio era mucho mayor, pero en los últimos años, según señaló, los grupos criminales comenzaron a asesinar a los asaltantes de los comercios, incluso también a policías que se supone «no andaban bien».

Puse un almacén, me dedicaba a la venta de uniformes. Alguien sabía que yo metía allí todo. Ese día llegué, guardé todo, y me fui. Cuando volví ya me habían sacado las ratas todo. Me quedé limpia, sin nada de dinero. (...) Yo sabía quiénes eran los rateros. No denunciamos, porque uno tiene miedo de la delincuencia, porque si no me hacen algo a mí, le pueden hacer a algún hijo. (...) Los que te asaltaban son del mismo gobierno. Fueron policías los que me asaltaron, pero ya a esa gente la mataron, ya no está. (...) Aquí casi acabaron con todos (los delincuentes), eran una plaga. ${ }^{11}$

En este sentido, los policías se presentan como actores importantes en la configuración de los escenarios de violencia. En el Sector Sur, los empresarios observan que los policías ahora están subordinados a las reglas que imponen los grupos delictivos. En el Sector Central, por el contrario, los empresarios que no tienen protección directa de los grupos delictivos ven a los policías como agentes con quienes hay que negociar a través de ciertos pagos, para que cumplan, por un lado, con su papel como autoridad y, por el otro, para evitar que los propios policías les roben.

\subsection{Normas y sanciones}

El análisis sobre las representaciones del crimen permite interpretar las formas culturales y los patrones de comportamiento de los actores respecto a la

11. Entrevista con Antonia, empresaria en el Sector Sur en Culiacán, Sinaloa, México. Realizada el 8 de mayo de 2014. 
violencia. A través de las narraciones de las experiencias de los empresarios, se puede observar que en cada lugar se llevan a cabo arreglos específicos, en los que se imponen diversos tipos de regulación que implican normas y sanciones; es decir, una solidaridad forzada y una violencia silenciosa particular (Maldonado, 2014a). Como se muestra a continuación, mientras que en el Sector Sur se ha establecido una protección territorial que resguarda sobre todo a los establecimientos de los vecinos, en el Sector Central, donde los lazos entre los actores son menores, la protección abarca solo algunas empresas que han establecido negociación directa con los criminales o que tienen participación con estos.

\subsection{Sector Central}

En el Sector Central, los empresarios manifestaron preocupación por el incremento en delitos como robos y asaltos, no así por la presencia de grupos o personajes relacionados con el narcotráfico, y tampoco por los homicidios. Mientras que algunos negocios expresaron sentirse o saber que son protegidos por los grupos criminales, otros se sienten vulnerables ante la delincuencia y han adaptado algunas estrategias de rutina para protegerse: dar propinas a los policías que patrullan la zona, identificar bien a los clientes e incluso rechazar a aquellos que les parezcan posibles delincuentes, instalar alarmas de seguridad y estar en constante contacto con los demás empresarios.

La experiencia de Carolina habla de la necesidad que tienen los empresarios de conocer y seguir los códigos de violencia para que sus negocios puedan sobrevivir. La empresaria estableció hace dos años una franquicia de una tienda de videojuegos; invirtió en imagen, publicidad; se hizo con una cartera de clientes, y estaba segura de que se encontraba en la mejor zona para establecer su empresa, excepto por el hecho de que no conocía la situación de violencia en el lugar: «Pensaba que era un barrio tranquilo. O sea, es una colonia bien, los narcos hacen mucho relajo, pero eso incluso era bueno, porque eran también nuestros clientes. Yo no sabía que (en ese lugar) asaltaban».12

Dos meses después de que Carolina abriera por primera vez las puertas de la tienda, unos ladrones la despojaron de casi toda la mercancía y el mobiliario. Esa mañana, se acercaron a hablarle los vecinos y otros empresarios del sitio, con quienes apenas había tenido contacto, y le hicieron saber todas aquellas reglas que hasta la fecha desconocía: desde reforzar la seguridad de su negocio hasta establecer alianzas con los policías o incluso con grupos delictivos. El negocio fracasó, en palabras de Carolina, "porque no conocía como se manejaban allí».

Daniel, Gustavo, Carolina y todos los entrevistados en el Sector Central lamentaron que los crímenes se hayan incrementado en el barrio durante los últimos años, donde, dijeron, se roban en promedio dos coches cada

12. Entrevista con Carolina, empresaria en el Sector Central en Culiacán, Sinaloa, México. Realizada el 7 de abril de 2014. 
día y a algunos negocios los asaltan hasta dos veces a la semana ${ }^{13}$. Gustavo, uno de los comerciantes, invirtió en alarmas, mejor iluminación y nuevos candados y aun así fue asaltado una noche, cuando cerraba las puertas. Una joyería, que se encuentra en frente de su negocio, la cual también tenía cámaras y un sistema de seguridad más sofisticado, también fue asaltada, según los vecinos, y se llevaron parte de la mercancía: «Se llevaron millones de pesos de aquí enfrente. Fue muy raro, porque las cámaras justo en ese momento no funcionaron. El dueño se fue a vivir a otra ciudad. (...) No sé si lo amenazaron». ${ }^{14}$

A pesar de la violencia, una parte importante de los empresarios sigue invirtiendo en el sitio, hace crecer sus negocios e incluso algunos tienen hasta dos sucursales en la colonia. Según ellos, la violencia no ha sido un limitante, porque, como explica Jorge, director general de una cadena regional de farmacias, «el riesgo es administrado»..$^{15}$

Incluso la violencia producida por los narcojuniors en las calles es tolerada por muchos de los empresarios entrevistados, como un «mal necesario», porque estos jóvenes también son consumidores en sus establecimientos. A Daniel, que tiene una heladería, no le molesta el caos de los fines de semana, porque piensa que eso atrae clientes.

El Sector Central también ha sido escenario de asesinatos y tiroteos relacionados con el narcotráfico, no obstante, sus corredores urbanos siguen siendo muy visitados. Daniel, entre otros entrevistados, expresó que existe una adaptación a la violencia:

Fíjate que yo estoy asombrado. Habiendo tanto relajo hay muy pocos muertos (...), la última persona que yo sé que mataron es esa muchachita que estudiaba en la FCA (Facultad de Contabilidad y Administración de Empresas), la mataron aquí, antes de llegar al bulevar. Y para atrás, hará unos cuatro años, al que balacearon aquí atrás fue a un hijo del JT. Esos son los dos últimos... nos hemos habituado a la violencia en la calle. ${ }^{16}$

A través de las historias, se puede observar que quienes trabajan y transitan en el Sector Central se han habituado a los crímenes y a las faltas al orden público. Los empresarios se adaptan y participan en las reglas de la calle: dan propinas a los policías, toleran comportamientos prepotentes y agresivos de los narcojuniors y, en ocasiones, son testigos silenciosos de homicidios y enfrentamientos armados. La construcción de una violencia silenciosa y la adopción a las reglas no escritas les permite, hasta cierto punto, protegerse de las sanciones y no ser víctimas en crímenes mayores — toleran algunos robos, pero consi-

13. Estos datos fueron proporcionados por los empresarios en entrevista.

14. Entrevista con Gustavo, empresario en el Sector Central en Culiacán, Sinaloa, México. Realizada el 9 de abril de 2014.

15. Entrevista con Jorge, empresario en el Sector Central en Culiacán, Sinaloa, México. Realizada el 10 de marzo de 2014.

16. Entrevista con Jorge. 
deran que al menos no son asesinados o despojados de sus mercancías porque "andan con cuidado ${ }^{17}$ ».

Si bien participan de los códigos como medida de protección, a través de la adopción de las normas o de establecer acuerdos directos con los criminales, esto no implica que dejen de llevar a cabo estrategias por su cuenta para protegerse, como instalar cámaras de seguridad y contratar guardias privados. Tanto criminales como empresarios y policías participan de los códigos de violencia en el sector. Algunos, imponiendo las reglas y sanciones, negociando protección, y otros, adaptándose a los códigos como estrategia de supervivencia.

\subsection{Sector Sur}

Los empresarios en el Sector Sur mencionaron que existe un aparente acuerdo entre los grupos delictivos para cuidar que «no se caliente» esa zona ${ }^{18}$. $\mathrm{Al}$ parecer, dicho acuerdo, consiste en que los grupos criminales del narcotráfico vigilan que no ocurran asaltos y robos en el sector, como estrategia para no llamar la atención de la prensa y de la opinión pública, pero también para construir una cierta relación de control de los residentes del lugar. Los grupos criminales se han convertido en una entidad que regula y controla la violencia, pues imponen por medio de la fuerza las reglas a seguir y las sanciones a los infractores. Los empresarios entrevistados han nombrado a los asesinos de asaltantes y ladrones del comercio como «la gente», «los malos» y «los que no andan bien».

Heriberto tiene una carnicería en el Sector Sur y recuerda cómo hace meses llegó un hombre de buen aspecto, en una camioneta de modelo reciente, que logró generarle confianza, pero resultó ser un ladrón. No obstante, al final, ese sujeto fue víctima de la sanción por sus actos, según cuenta el empresario:

(...) El tipo comenzó a pedirme muchas cosas, mucha carne para asar, de la mejor, muchas cosas. (...) Cuando tuvo todo arriba, se subió también a la camioneta... «iEh!» — le dije — «iHey, compa, la feria!». Y nomás me gritó: «Te ves pariente!». Y ese mismo morro se fue pa’rriba y allá hizo lo mismo, en la gasolinera, en el expendio [de cerveza] y en otras tiendas. Quien sabe qué traía, andaba ondeando el chamaco, arrasando. jJum! Como a los diez días, amaneció muerto en Sanalona, y yo no fui eh, yo no fui, jajajaaja. [iQ Que si cómo lo sé?] Pues por la policía que le cuenta a uno y [el periódico] El Debate. [¿Que si cómo sé que era el mismo?] Es que ese tipo ya había hecho varias. Los

17. Con la expresión de «andan con cuidado», los empresarios se refieren a que no desafían el orden que impone el crimen: no denuncian o testifican sobre los asesinatos, sobre las faltas al orden público de los narcos y sus familiares, como detonaciones de armas de fuego, dan propinas a los policías sin cuestionarlos.

18. La expresión «zona caliente» se refiere a la situación en la que se encuentra un territorio cuando los incidentes violentos se vuelven muy frecuentes o muy agresivos. Según los empresarios, en el corredor Sur, los grupos criminales cuidan de que no se incrementen los delitos en esas colonias, porque esto atraería la atención pública hacia ese sector. 
policías le cuentan a uno. Aquí somos muy mitoteros ${ }^{19}$, $\operatorname{conocemos}$ a todos aquí, y todos lo conocen a uno. Todo nos decimos. ${ }^{20}$

A pesar de que los comerciantes reportan que los asaltantes y ladrones son sancionados con violencia, no todos los delincuentes siguen los códigos de conducta impuestos por los grupos criminales, sobre todo los delincuentes de oportunidad, que atracan pequeños establecimientos de cadenas comerciales y que son adictos a las drogas, según explican los empresarios. En las entrevistas, se refieren a estos sujetos como «tarántulas». De esto habló Julia, una joven de 32 años que trabaja por las noches en una farmacia en el sector, acompañada solamente de otra mujer. La joven considera que el principal problema que enfrentan son los asaltos ${ }^{21}$.

En el minúsculo local de unos $20 \mathrm{~m}$, la joven de complexión pequeña se refugiaba detrás de un aparador, mientras describía sus experiencias con los asaltantes, que, según contó, han sido identificados por los vecinos y asesinados por los criminales:

[...] A mí me ha tocado aquí... una, dos, tres veces. Las dos primeras fue el mismo tipo; la primera, venía barbón, después se quitó la barba [...] Desafortunadamente, los asaltantes son de las colonias como dicen «aledañas». ¿Cómo lo sé? Porque los vecinos nos preguntan: «¿Y cómo era [el asaltante]?» Y cuando uno les dice, se quedan: «Ah, sí, es fulanito, el que vive atrás... ha de haber andado bien mariguano, oiga». Una vez, le dije al señor [al dueño de la farmacia]: «Oiga, dicen que es fulatino». Y él me respondió: «Vamos a echarle a la poli». Pero no, a la semana, lo mataron [al asaltante]. De hecho, se agarró racha de que a todos los asaltafarmacias los estaban matando. Te lo digo porque yo trabajaba en una cadena de farmacias que a cada rato sale en el periódico. Los asaltos que yo he tenido aquí no son nada comparados con los que tenía allá. Allí sí te ponen la pistola en la cabeza, el cuchillo, y eso no sale a la luz. Ahí que les den [muerte] a todos, pa’ qué los dejan, solo están estorbando en este mundo.

Los empresarios en el Sector Sur no solo aceptan la situación de violencia en sus comunidades, sino que algunos de ellos se congratulan de que los grupos criminales traten de parar, por medios violentos, a ciertos delincuentes que roban o asaltan. Esto puede entenderse como un mecanismo de construcción de la violencia silenciosa, a través de la cual se justifica la actuación de los grupos armados. Al preguntarles por el papel de la policía ante esta situación, mencionaron que los cuerpos de seguridad están enterados, como ellos, y que nada hacen o pueden hacer al respecto. De esta manera parece ser que tanto los

19. Mitotero es un regionalismo usual en Sinaloa. Se refiere a una persona a quien le gusta conocer y comunicar rumores.

20. Entrevista con Heriberto, empresario en el Sector Sur, en Culiacán, Sinaloa, México. Realizada el 5 de abril de 2014.

21. Entrevista con Julia, empleada en una farmacia del Sector Sur, en Culiacán, Sinaloa, México. Realizada el 5 de abril de 2014. 
empresarios como los policías y ladrones se ven obligados a aceptar los códigos de comportamiento que impone el narcotráfico en la comunidad, y al hacerlo contribuyen a su reproducción. Una solidaridad forzada que instituye un orden particular en estas comunidades.

\section{Conclusiones}

El análisis de los códigos de violencia en espacios comerciales de Culiacán revela cómo en escenarios con alta incidencia delictiva los empresarios se ven en la necesidad de mediar y contener la violencia, tratando de adecuar, negociar y arreglar las imposiciones de los grupos del crimen y las autoridades, con el fin de garantizar un cierto orden que les permita el desarrollo de sus actividades. En este sentido, los empresarios en esta ciudad no solo están sujetos a la imposición de un cierto orden, sino que contribuyen activamente en su reproducción - en diferentes grados de poder-y también participan en su definición. De alguna manera, entonces, se les impone y producen ciertos códigos de violencia, y contribuyen a la construcción de solidaridades forzadas y silencios. En la medida en que establecen arreglos directos para recibir protección —en formas que implican, a veces, la generación de mayor violencia-, reconocen, se adaptan y adoptan los regímenes que establecen los grupos criminales.

Este tipo de observaciones permite concluir que, en ciertos espacios urbanos, como los que aquí se han analizado, las relaciones rutinarias y estratégicas que establecen la diversidad de actores transforman territorios e identidades (Maldonado, 2012). Estos códigos se establecen tanto en las zonas marginadas de la ciudad como en las de estratos altos, y varían según la gestión territorial que establece el narcotráfico para garantizar el funcionamiento de sus negocios y evitar que la atención pública recaiga sobre ellos. Si la gestión del narcotráfico sobre el territorio se orienta hacia el control general, como sucede en las zonas marginadas, sobre empresarios y policías se impone un conjunto de códigos y solidaridades forzadas, que todos deben respetar. Y si la presencia del crimen no implica la gestión general de un territorio, como ocurre en los sectores de estratos altos, los empresarios construyen códigos de violencia diferenciales, en función de si se trata de la policía o de grupos criminales.

En el Sector Sur, los grupos criminales del narcotráfico que mantienen el control territorial de la violencia se encargan de vigilar y castigar a quienes asaltan y roban al comercio local. Los empresarios siguen diferentes códigos para mantenerse seguros: identifican a los «que andan mal», se mantienen en contacto con otros empresarios, establecen relaciones con los policías - bajo el entendido de que estos últimos funcionan bajo el orden establecido por los grupos criminales-, respetan la presencia de los grupos del narcotráfico y normalizan actos de violencia de mayor escala, como los homicidios. Asimismo, hay un reconocimiento claro de las implicaciones de no seguir estos códigos: ser asesinado.

En el Sector Central, en cambio, la regulación de la violencia se define en función de acuerdos específicos: entre algunos empresarios y los grupos 
del narcotráfico, entre policías y empresarios, y entre los narcojuniors y los empresarios. Algunos empresarios que mantienen negociaciones con criminales consiguen protección y defensa contra los robos y los asaltos, mientras otros establecen negociaciones informales con la policía, a través de propinas para tener cierta protección. El resto trata de defenderse y protegerse de los robos y asaltos con la adquisición de alarmas y mecanismos privados de seguridad. La presencia de narcojuniors en este sector, con sus conductas desafiantes de las normas oficiales, es un factor importante en la definición de los códigos de comportamiento para el resto de los actores.

En Culiacán, donde el crimen —el narcotráfico y la delincuencia comúnha intervenido en gran parte de los ámbitos sociales y en casi todos los espacios, integrando sus propias formas culturales (Polit, 2014), los códigos de violencia se establecen y gobiernan en los diferentes sectores. Sus habitantes no los consideran espacios de caos, porque se han construido órdenes de control y porque participan o se han adaptado a estas situaciones. Las narraciones muestran que tanto la sociedad como los delincuentes establecen y siguen acuerdos informales, los cuales les permiten realizar sus actividades con cierta confianza. Es decir, se ha normalizado la violencia y los empresarios consideran que enfrentar el riesgo «es parte de trabajar en Culiacán».

Finalmente, siguiendo a Maldonado (2014b), este trabajo analítico, centrado en la vida cotidiana de actores que residen en territorios con problemas de narcotráfico y crimen organizado, puede constituir un buen punto de partida para entender cómo distintos sectores sociales — clases medias, trabajadores, comerciantes y empresarios- sortean el día a día de la violencia que impera en el país.

\section{Referencias bibliográficas}

Anderson, Elijah (1999). Codes of the street. Decency, violence and moral life in the inner city. Nueva York: Norton and Company.

Arteaga, Nelson; Gayet, Cecilia y Alegría, Alejandro (2016). «Uso del tiempo libre, jóvenes y delito en México». Economía, sociedad y territorio, 16 (52), 623-650. <https://doi.org/10.22136/est0522016575>.

BRUCE, Jacobs y WRIGHT, Richard (2010). «Bounded rationality, retaliation, and the spread of urban violence». Journal of Interpersonal Violence, 25 (10), 1739-1766. <https://doi.org/10.1177/0886260509354502>.

COAFFE Jon; WOOD, David y Rogers, Peter (2009). The everyday resilience of the city. Londres: Palgrave.

COHEN, Lawrense y FELSON, Marcus (1979). «Social change and crime rate trends: A routine activity approach». American Sociological Review, 44 (4), 588-608. $<$ https://doi.org/10.2307/2094589>.

EL UNIVERSAL (2014). «Narcojuniors y pandillas prenden focos rojos en norte». El Universal, jueves 6 de noviembre de 2014.

- (1997). Modernidad e identidad del yo. El yo y la sociedad en la época contemporánea. Barcelona: Península.

- (2003). La constitución de la sociedad, bases para la teoría de la estructuración. Argentina: Amorrortu. 
Green, Eileen y Singleton, Carrie (2006). «Risky bodies at leisure: Young women negotiating space and place». Sociology, 40 (5), 853-871. $<$ https://doi.org/10.1177/0038038506067510>.

HeITGERD, Janet y BURSIK, Robert (1987). «Extra community dynamics and the ecology of delinquency». British Journal of Sociology, 94 (4), 775-787. $<$ https://doi.org/10.1111/j.1745-9125.1997.tb01235.x>.

Hindelang, Michel; GotTfredson, Michael y Garofalo, James (1978). Victims of personal crime: An empirical foundation for a theory of personal victimization. Ballinger: Cambridge.

Instituto Nacional de Estadística y Geografía (INEGI) (2010). Censo de población y vivienda 2010 para Culiacán, Sinaloa, SCINCE. México: INEGI.

- (2010a). Directorio Nacional de Unidades Económicas (DENUE) para la ciudad de Culiacán, Sinaloa. México: INEGI.

JACOBS, Bruce y WRIGHT, Richard (2010). «Bounded rationality, retaliation, and the spread of urban violence». Journal of Interpersonal Violence, 25, 1739-1766. <https://doi.org/10.1177/0886260509354502>.

LuPTON, Deborah (1999). «Dangerous places and the unpredictable stranger: Constructions of fear of crime». The Australian and New Zealand Journal of Criminology, $32(1), 1-15$. <https://doi.org/10.1177/000486589903200102>.

MALDONADO, Salvador. (2012). «Drogas, violencia y militarización en el México rural: el caso de Michoacán». Revista Mexicana de Sociología, 74 (1), 5-39.

- (2014a). «You don't see any violence here but it leads to very ugly things: Forced solidarity and silent violence in Michoacán, Mexico». Dialectical Anthropology, 38 (2), 153-171. <https://doi.org/10.1007/s10624-014-9335-4>.

- (2014b). «Despejando caminos inseguros: Itinerarios de una investigación sobre la violencia en México». Alteridades, 24 (47), 63-76.

Matsueda, Ross L.; Drakulich, Kevin y Kubrin, Charis E. (2006). «Race and neighborhood codes of violence». En: PETERSON, Ruth D. y KRIVO, Lauren J. (eds.). The many colors of crime: Inequalities of race, ethnicity, and crime in America. Nueva York: New York University Press.

POLIT DueÑAs, Gabriela (2014). «De cómo leer el narcotráfico y otras advertencias». Apuntes de investigación del CECYP, 24, 177-185.

Secretaría de Desarrollo Social (Sedesol) (2012). Programa Municipal de Desarrollo Urbano de Culiacán (PMDUC). México: Instituto Municipal de Planeación Urbana de Culiacán.

Secretaría de Seguridad Pública y Tránsito Municipal de Culiacán (SSPyTM) (2011). Datos de delitos reportados a los números de emergencia y número de individuos detenidos según colonia en la ciudad de Culiacán, años 2000-2010. Datos proporcionados en el 2011 por la Secretaría.

SENNETT, Richard (2012). Juntos. Rituales, placeres y politica de cooperación. Barcelona: Anagrama.

Threadgold, Steven y Nilan, Pam (2009). «Reflexivity of contemporary youth, risk and cultural capital». Current Sociology, 57 (1), 47-68. $<$ https://doi.org/10.1177/0011392108097452>.

TSELONI, Aandromiche y FARRELL, Graham (2002). «Burglary victimization across Europe: The roles of prior victimization, micro and macro-level routine activities». En: NieuWBeERTA, Paul (ed.). Crime victimization in comparative perspective. Annandale: The Federation Press. 
WalkLate, Sandra (1998). "Crime and community fear or trust?». British Journal of Sociology, 94 (4), 550-569. <https://doi.org/10.2307/591288>.

- (2001). «Fearful communities?». Urban Studies, 38 (5-6), 929-939. <https://doi.org/10.1080/00420980120046617>.

- (2011). «Reframing criminal victimization: Finding a place for vulnerability and resilience». Theoretical Criminology, 15 (2), 179-194. <https://doi.org/10.1177/1362480610383452>.

Wilcox, Pamela; Land, Kenneth y Hunt, Scott (2003). Criminal circumstance: A dynamic multicontextual criminal opportunity theory. Nueva York: Aldine. $<$ https://doi.org/10.1353/cjs.2004.0013>.

\section{Anexo metodológico}

Entrevista con Carmen, empresaria en el Sector Sur en Culiacán, Sinaloa, México. Realizada el 23 de abril de 2014.

Entrevista con Josué, empresario en el Sector Sur en Culiacán, Sinaloa, México. Realizada el 15 de marzo de 2014.

Entrevista con Antonio, empresario en el Sector Central en Culiacán, Sinaloa, México. Realizada el 26 de abril de 2014.

Entrevista con Candelario, empresario en el Sector Sur en Culiacán, Sinaloa, México. Realizada el 10 de marzo de 2014.

Entrevista con Gustavo, empresario en el Sector Central en Culiacán, Sinaloa, México. Realizada el 9 de abril de 2014.

Entrevista con Heriberto, empresario en el Sector Sur en Culiacán, Sinaloa, México. Realizada el 5 de abril de 2014.

Entrevista con Antonia, empresaria en el Sector Sur en Culiacán, Sinaloa, México. Realizada el 8 de mayo de 2014.

Entrevista con Carolina, empresaria en el Sector Central en Culiacán, Sinaloa, México. Realizada el 7 de abril de 2014.

Entrevista con Heriberto, empresario en el Sector Sur en Culiacán, Sinaloa, México. Realizada el 5 de abril de 2014.

Entrevista con Julia, empleada en una farmacia el Sector Sur en Culiacán, Sinaloa, México. Realizada el 5 de abril de 2014. 
